\title{
Price discrimination in asymmetric Cournot oligopoly
}

\author{
Barna Bakó* \\ Corvinus University of Budapest \\ Department of Microeconomics \\ Fővám tér 8 \\ H-1085 Budapest, Hungary, \\ e-mail: barna.bako@uni-corvinus.hu
}

\begin{abstract}
In this article we examine the effects of third degree price discrimination in asymmetric Cournot oligopolies. We show that the average price is not affected by the extent of price discrimination. We find that the asymmetry between firms is reflected only by the output produced for the lowest-valuation consumers and firms produce equal quantities to the other consumer groups.
\end{abstract}

JEL codes: D43

Keywords: price discrimination, Cournot oligopoly

\section{Introduction}

There is an emerging literature dealing with non-linear pricing in oligopolies. ${ }^{1}$ Hazledine (2006) examines third degree price discrimination in a symmetric Cournot model, where firms are able to segment their consumers by ranges of reservation price. Consumer with reservation price between $r_{i-1}$ and $r_{i}$ pay one price, those between $r_{i}$ and $r_{i+1}$ pay another, and so on. In this framework, he

* The author gratefully acknowledges financial support from the Corvinus University of Budapest through the Talentum Program and the TAMOP-4.2.2/B- 10/1-2010-0023 fellowship.

${ }^{1}$ For a general overview of the literature on price discrimination, see Stole (2007) 
shows that the output sold at a particular price is a multiple $n$ of the output sold at the next lowest price, where $n$ is the number of firms in the market. Furthermore, he finds that the average price charged does not depend on the number of different prices offered. Kutlu (2009) analyzes the effect of second degree price discrimination in the Stackelberg competition model, and shows that the follower firm does all price discrimination, while the leader firm has an incentive not to price discriminate at all. However, this result is not robust if the marginal cost of the leader is lower than that of the follower. Arijit (2010) shows that in this case both firms practice price discrimination.

In this paper we examine second degree price discrimination as modeled by Hazledine (2006) but instead of using a symmetric setup we introduce asymmetric firms. Our main finding is that in any asymmetric Cournot oligopoly the output-weighted average price is not dependent on the extent of price discrimination, hence the standard single-price Cournot model does not mislead in this respect.

\section{The model and the results}

Consider an asymmetric Cournot oligopoly. Firms produce homogenous product with constant marginal costs. There are two types of firm (1 and 2$)$ which differ in their marginal costs. The marginal costs of type $j(j=1,2)$ is $c_{j}$, with $c_{2}>c_{1} \geq 0$. Thus, type 1 is more cost effective than type 2. For the sake of tractability we define $c \equiv c_{2}-c_{1}$. Consumers differ in their valuation and each one buys at most one unit of the good. Firms know the valuation of the consumers and can prevent resale of the good.

We assume that firms divide the consumers into different groups $(K)$ according to their valuation. The price of the good for the group $k^{t h}(\leq K)$ is given by

$$
p^{k}=a-Q^{k}
$$

where $Q^{k} \equiv \sum_{i=1}^{k}\left(\sum_{s=1}^{l} q_{1 s}^{i}+\sum_{r=1}^{m} q_{2 r}^{i}\right)$ is the total quantity sold to all groups from 1 to $k$, and $l$ denotes the number of the firms of type 1 and $m$ the number of type 2 , respectively. We simplify our model by assuming that $l=m=1$, though it is possible to show that our results hold in the general case as well.

To motivate such a setting consider an airline industry, where the tickets are purchased in unit quantity and it is a standard practice to price discriminate. Consumers usually come to the market at different times and their valuations is negatively correlated with the length of time between purchase and the actual flight (see Gale (1993)).

Given the demand and cost functions, firm $j$ 's decision problem consist of offering quantity menu $\left(q_{j}^{1}, q_{j}^{2}, \ldots q_{j}^{K}\right)$ that maximizes its profit, given the other firm's quantities. Formally, this can be written as:

$$
\max _{q_{j}^{1}, q_{j}^{2}, \ldots, q_{J}^{K}} \pi_{j}=\sum_{k=1}^{K}\left(p^{k}-c_{j}\right) q_{j}^{k}
$$




$$
\begin{aligned}
= & \left(a-q_{j}^{1}-q_{-j}^{1}-c_{j}\right) q_{j}^{1} \\
& +\left(a-q_{j}^{1}-q_{-j}^{1}-q_{j}^{2}-q_{-j}^{2}-c_{j}\right) q_{j}^{2} \\
& \vdots \\
& +\left(a-q_{j}^{1}-q_{-j}^{1}-q_{j}^{2}-q_{-j}^{2}-\ldots-q_{j}^{K}-q_{-j}^{K}-c_{j}\right) q_{j}^{K}
\end{aligned}
$$

where $q_{-j}^{k}$ stands for the quantity offered by the other firm to the consumer group $k$ and $j \neq-j$.

Deriving (2) with respect to the decision variables $q_{j}^{k}$ we get the first order condition for the profit maximization. The first order conditions can be written as follows:

$$
\frac{\partial \pi_{j}}{\partial q_{j}^{k}}=a-c_{j}-\sum_{i=1}^{K} q_{j}^{i}-q_{j}^{k}-\sum_{i=1}^{k} q_{-j}^{i}=0
$$

for all $k=1,2, \ldots, K$ and $j=1,2$. Then, subtracting the $k+1^{\text {th }}$ from $k^{t h}$ equation we have:

$$
q_{j}^{k+1}-q_{j}^{k}+q_{-j}^{k+1}=0
$$

for $j=1,2$. Summing these expressions over $j$ yields:

$$
q_{j}^{k}+q_{-j}^{k}=2\left(q_{j}^{k+1}+q_{-j}^{k+1}\right)
$$

or

$$
q_{j}^{k}+q_{-j}^{k}=2^{K-k}\left(q_{j}^{K}+q_{-j}^{K}\right)
$$

The following result is immediate from the above discussion.

Proposition 1 Price discrimination in an asymmetric Cournot oligopoly results in an output sold to the consumer group $k$ being multiple of the output sold to the consumer group $k+1$.

The reason for this behavior is that firms incentives to offer a higher quantity is increasing in prices.

Furthermore, for $k=1$ equation (3) simplifies to

$$
a-c_{j}-\sum_{i=1}^{K} q_{j}^{i}-q_{j}^{1}-q_{-j}^{1}=0
$$

for $j=1,2$ and $j \neq-j$. Subtracting these equations from each other over $j$ yields

$$
\sum_{i=1}^{K} q_{j}^{i}=\sum_{i=1}^{K} q_{-j}^{i}+c
$$


Plugging this into the $k^{\text {th }}$ first order conditions we can write:

$$
q_{j}^{k}+\sum_{i=1}^{k} q_{-j}^{i}=q_{-j}^{k}+\sum_{i=1}^{k} q_{j}^{i}
$$

or

$$
\sum_{i=1}^{k-1} q_{j}^{i}=\sum_{i=1}^{k-1} q_{-j}^{i}
$$

This implies that

$$
\begin{aligned}
q_{j}^{k} & =q_{-j}^{k} \quad \text { for every } \quad k=1,2, \ldots, K-1 . \\
q_{j}^{K} & =q_{-j}^{K}+c .
\end{aligned}
$$

Both firms produce the same output for each consumer group with a relatively high valuation and the asymmetry between firms is reflected only by the output offered for the lowest valuation consumers.

Proposition 2 In an asymmetric Cournot oligopoly each firm produce equal quantity in every segment except the lowest valuation sub-market for which the cost effective firms offer a quantity bigger with $c$ than the high cost firms.

To calculate the equilibrium quantities consider the followings. Proposition (2) and equation (6) implies that $q_{j}^{k}=2^{K-k-1}\left(2 q_{2}^{K}+c\right)$ for every $k=$ $1,2, \ldots, K-1$ and $j=1,2$. Then

$$
\begin{aligned}
\sum_{i=1}^{K-1} q_{j}^{k} & =\sum_{i=1}^{K-1} 2^{K-k-1}\left(2 q_{2}^{K}+c\right) \\
& =\left(2^{K-1}-1\right)\left(2 q_{2}^{K}+c\right)
\end{aligned}
$$

Now, plugging this into the (3) when $k=K$ yields:

$$
\begin{aligned}
0 & =a-c_{j}-\sum_{i=1}^{K} q_{j}^{i}-q_{j}^{K}-\sum_{i=1}^{K} q_{-j}^{i} \\
& =a-c_{j}-\left(\sum_{i=1}^{K-1} q_{j}^{i}+q_{j}^{K}\right)-q_{j}^{K}-\left(\sum_{i=1}^{K-1} q_{-j}^{i}+q_{-j}^{K}\right) \\
& =a-2 \sum_{i=1}^{K-1} q_{j}^{i}-3 q_{2}^{K}-2 c
\end{aligned}
$$

Substituting (12) into (13) implies

Proposition 3 In an asymmetric Cournot oligopoly price discrimination results in the following equilibrium quantities $(k=1, \ldots, K-1$ and $j=1,2)$ :

$$
q_{j}^{k}=\frac{\left(2^{K-k-1}\right)(2 a-c)}{2^{K+1}-1}, \quad q_{1}^{K}=\frac{a+\left(2^{K}-1\right) c}{2^{K+1}-1} \quad q_{2}^{K}=\frac{a-2^{K} c}{2^{K+1}-1}
$$


To examine the implication of price discrimination for the average price charged in the market we define the output-weighted average price as follows:

$$
p_{a v}^{K} \equiv \sum_{k=1}^{K} \frac{p^{i}\left(q_{j}^{i}+q_{-j}^{i}\right)}{Q^{K}}
$$

Theorem 1 In an asymmetric Cournot oligopoly the output-weighted average price does not depend on the extent of price discrimination. That is, for any $K$ and $c$

$$
p_{a v}^{K}=p_{a v}^{K+1}
$$

Proof. Substituting (12) into $Q^{K}=2 \sum_{i=1}^{K-1} q_{j}^{i}+q_{1}^{K}+q_{2}^{K}$ we have that:

$$
Q^{K}=\left(2^{K}-1\right)\left(2 q_{2}^{K}+c\right)
$$

Then, Proposition (3) yields:

$$
q_{j}^{k}+q_{-j}^{k}=\left(2^{K-k}\right)\left(2 q_{2}^{K}+c\right)
$$

Using (1), the prices charged in the segment $k$ can be written as:

$$
p^{k}=a-\sum_{i=1}^{k}\left(q_{j}^{i}+q_{-j}^{i}\right)=a-\left(2 q_{2}^{K}+c\right)\left(2^{K}-2^{K-k}\right)
$$

Hence, the output-weighted average price charged simplifies to:

$$
p_{a v}^{K}=\sum_{i=1}^{K}\left(\left(\frac{2^{K-i}}{2^{K}-1}\right)\left(a-\left(2 q_{2}^{K}+c\right)\left(2^{K}-2^{K-i}\right)\right)\right)
$$

Substituting into this the equilibrium value given by Proposition (3) for $q_{2}^{K}$, straightforward calculation yields:

$$
p_{a v}^{K}=\frac{1}{\left(2^{K}-1\right)\left(2^{K+1}-1\right)} \sum_{i=1}^{K}\left(2^{K-i}\left(2^{K-i+1}-1\right) a+2^{K-i}\left(2^{K}-2^{K-i}\right) c\right)
$$

for any $K$ and $c$. Thus, the output-weighted average price for $K+1$ can be written as:

$$
\begin{gathered}
p_{a v}^{K+1}=\frac{1}{\left(2^{K+1}-1\right)\left(2^{K+2}-1\right)} \quad \sum_{i=1}^{K+1}\left(2^{K-i+1}\left(2^{K-i+2}-1\right) a+2^{K-i+1}\left(2^{K+1}\right.\right. \\
\left.\left.-2^{K-i+1}\right) c\right)
\end{gathered}
$$

This leaves us to show that:

(i) $\left(2^{K+2}-1\right) \sum_{i=1}^{K}\left(2^{K-i}\left(2^{K-i+1}-1\right)\right)=\left(2^{K}-1\right) \sum_{i=1}^{K+1}\left(2^{K-i+1}\left(2^{K-i+2}-1\right)\right)$ 
(ii) $\left(2^{K+2}-1\right) \sum_{i=1}^{K}\left(2^{K-i}\left(2^{K}-2^{K-i}\right)\right)=\left(2^{K}-1\right) \sum_{i=1}^{K+1}\left(2^{K-i+1}\left(2^{K+1}-\right.\right.$
$\left.\left.2^{K-i+1}\right)\right)$

First consider (i). The sum at the LHS can be written as:

$$
\begin{aligned}
\sum_{i=1}^{K}\left(2^{K-i}\left(2^{K-i+1}-1\right)\right) & =\sum_{I=1}^{K} 2^{2 K-2 i+1}-\sum_{I=1}^{K} 2^{K-i} \\
& =\sum_{i=1}^{K} 2\left(4^{K-i}\right)-\sum_{i=1}^{K} 2^{K-i} \\
& =2\left(\frac{4^{K}-1}{3}\right)-\left(2^{K}-1\right)
\end{aligned}
$$

Thus, the LHS simplifies to:

$$
\begin{aligned}
\left(2^{K+2}-1\right)\left(\frac{2}{3}\left(4^{K}-1\right)-\left(2^{K}-1\right)\right)= & \frac{2}{3} 2^{K+2} 4^{K}+\frac{1}{3} 2^{K+2}-2^{2 K+2}-\frac{2}{3} 4^{K} \\
& +2^{K} \\
= & \frac{8\left(8^{K}\right)-14\left(4^{K}\right)+7\left(2^{K}\right)}{3}
\end{aligned}
$$

In the same way we can prove that the RHS can be written as

$$
\begin{aligned}
\left(2^{K}-1\right) \sum_{i=1}^{K+!}\left(2^{K-i+1}\left(2^{K-i+2}-1\right)\right)= & \left(2^{K}-1\right)\left(\frac{2}{3}\left(4^{K+1}-1\right)-\left(2^{K+1}-1\right)\right) \\
= & \frac{2}{3} 2^{K} 4^{K+1}+\frac{1}{3} 2^{K}-2^{2 K+1}-\frac{2}{3} 4^{K+1} \\
& +2^{K+1} \\
= & \frac{8\left(8^{K}\right)-14\left(4^{K}\right)+7\left(2^{K}\right)}{3}
\end{aligned}
$$

which proves that (i) is true for any $K$ and $c$.

Using the same technique it is easy to show that condition (ii) always holds for any $K$ and $c$.

\section{Conclusion}

In this paper we have shown that the output-weighted average price charged in an asymmetric Cournot oligopoly model does not depend on the extent of price discrimination. Under cost asymmetry firms produce equal outputs for the most of consumer groups and only the lowest valuation group is being offered with a higher quantity by the cost effective firm. We show that in every segment the output sold at a particular price is a multiple of the output sold at the next lowest price. 


\section{References}

Arijit, M. (2010), 'Price discrimination in oligopoly with asymmetric firms', Economics Bulletin, 2668-2670.

Gale, I. (1993), 'Price dispersion in a market with advance-purchases' Review of Industrial Organization, 451-464.

Hazledine, T. (2006), 'Price discrimination in Cournot-Nash oligopoly', Economics Letters, 413-420.

Kutlu, L. (2009), 'Price discrimination in Stackelberg competition', Journal of Industrial Economics, 364-368.

Stole, L. A. (2007), 'Price discrimination and competition', M. Armstrong and R. Porter (ed.), Handbook of Industrial Organization, 2221-2299. 